\title{
The Value of Anthropology in Child Health Policy
}

\section{Julie Spray}

\begin{abstract}
Aвstract: Working at the nexus of medical anthropology and the anthropology of childhood, this article challenges three assumptions often embedded in child health policy: (1) children are the passive recipients of healthcare; (2) children's knowledge of illness and their body can be assumed based on adult understandings; and (3) children's healthcare can be isolated from their social relations. I explore these themes through the case study of a $2011 \mathrm{New}$ Zealand government initiative to reduce the rates of rheumatic fever affecting low-income Māori and Pasifika children. Drawing on fieldwork with around 80 children at an Auckland primary school, I show how the 'sore throat' programme does not merely treat streptococcus A infections, but plays an active role in constituting children's experiences and understandings of their bodies and illness, and in shaping healthcare practices in ways unintended by policy-makers.
\end{abstract}

KeYwords: child-centred anthropology, childhood, health policy, health promotion, New Zealand, rheumatic fever, streptococcus A

Though few researchers work at the nexus of medical anthropology and child-centred anthropology, there is a long history of important contributions from social science to child health policy. Often drawing from ethnographic data and listening for the perspectives of children themselves, this research is valuable for its challenges to ethnocentric assumptions often embedded in health policy which privilege adult knowledge and experience. A very early example is the work of Myra Bluebond-Langner (1978) with terminally ill paediatric cancer patients, which challenged assumptions about children's knowledge and agency, and led to a reshaping of best practices for supporting dying children. Fifteen years later, Priscilla Alderson (1993) raised the issue of children's rights and autonomy in making medical decisions, specifically with reference to their consent to surgery. Sociologist Berry Mayall $(1996,1998)$ spoke directly to health and education policy in the UK, challenging ideologies which separate children's intellectual development from their physical care and well-being, and revealed contradictions between the rhetoric of 'health-promoting schools' and the realities of children's lived experience of health at school.
All of these scholars work within a constructivist framework which was concretised within childhood studies in the early 1990s (James and Prout 1990). Emphasising the value of children's own perspectives, this framework positions children as autonomous agents in their own healthcare, but it also positions them as a group that is often socially marginalised by its members' physical and structural dependency. A significant contribution of anthropology to child studies in recent decades has been to use ethnographic approaches to situate children as social actors within complex historical, politicoeconomic and sociocultural webs which structure, enable and constrain their agency. This view of children's practices as embedded within social relations and structural contexts can reveal otherwise invisible dynamics that may predict or explain the effects of policy interventions. For example, while economic circumstances drive children into prostitution in Thailand, Heather Montgomery (2001) details how these children form peer status hierarchies based on the degree to which they can control their choices of clients and those of other children. This means that all children aspire to pimping, and thus take an 
active role in perpetuating the oppression of their peers. Jean Hunleth (2017) describes how, in the context of the HIV/AIDS epidemic in Zambia, high adult mortality coupled with discourses of orphanhood designed to elicit sympathy and mobilise resources contribute to an enhanced sense of vulnerability among children, who in turn respond with strategies of 'getting closer' by taking responsibility for aspects of their parents' care in order to establish interdependence, or by resisting relocation away from infected parents. These practices of closeness run counter to health initiatives which try to prevent contagion and protect 'vulnerable' children from infection. Writing about Danish schoolchildren, Pia Haudrup Christensen (1999) elucidates the processes through which children construct health knowledge, health practices and symbolic meanings that are structured by institutions, wider sets of social relations, and cultural frames. A school space designated for ill children to rest which doubles as a disciplinary space therefore stigmatises healthcare from the perspectives of children. Collectively, this line of research indicates that structural conditions, including those produced by well-intentioned policy, cannot be disaggregated from the agentive practices that children construct around them.

In the present article, I use the case of a specific health intervention, the 2011 New Zealand Rheumatic Fever Prevention Programme (RFPP), to consider how policy becomes enfolded within and restructures the social, interpretive and embodied processes through which children construct their own cultural knowledge and social worlds. The problem here is that the child who is invisible in policy is very much active in the co-production of their health, as suggested by the work of Montgomery, Hunleth and Christensen referred to above, and policy which does not account for children's agency may result in unintended experiences, practices and outcomes.

Unfortunately, this understanding of childhood does not tend to be reflected in New Zealand policy, which often focusses on improving health and developmental outcomes with less regard for the child's lived experience of those policies. The New Zealand government has recently been criticised for inadequately prioritising child wellbeing, while even policy which directly affects children does not meaningfully consider the perspectives of children (D'Souza et al. 2017). Instead, the public policy approach to children has increasingly been oriented towards children's protection via the regulation of their lives (Tap 2007) within a social investment paradigm concerned with maximising human capital development and minimising future expense (Elizabeth and Larner 2009; Keddell 2018; O'Brien 2016). Assumptions of child passivity, vulnerability and incompetence may underlie the lack of attention paid to children's experience of health policy and of the body itself. Drawing from my analysis of the RFPP initiative, I point to three assumptions commonly underpinning child health policy that child-centred anthropology may challenge: first, that children are the passive recipients of healthcare; second, that children's understandings of illness and their bodies can be assumed based on adult models; and third, that children's healthcare can be isolated from their social relations.

\section{Rheumatic Fever and the 'Sore Throat' Clinic}

Rheumatic fever is an autoimmune response to an infection with group A streptococcus (GAS) bacteria, which is most commonly a strep throat infection. Affecting mainly children between 5 and 14 years old, the major concern is inflammation of the heart (carditis), as this may cause cardiac valve stenosis or 'heart damage', which in turn can lead to chronic rheumatic heart disease in later life (Jaine et al. 2008; Milne et al. 2012a). Children who develop rheumatic fever experience a lengthy hospital stay followed by ten years of monthly prophylactic penicillin injections, as recurrences are common for susceptible individuals.

The rate of rheumatic fever in New Zealand increased by 59\% between 1993 and 2009 (Milne et al. 2012b), driven by a startling disparity between rising incidences for Māori and Pasifika children and dwindling rates for non-Māori/Pasifika (primarily New Zealand European) children (Jaine et al. 2008). Mean incidence rates between 2000 and 2009 were 40.2 (per 100,000) for Māori children and 81.2 for Pasifika children compared to just 2.1 for non-Māori/Pasifika children. While there does appear to be a genetic susceptibility to rheumatic fever which affects about $3 \%-6 \%$ of individuals, this is evenly distributed across populations and there is no evidence that population genetic variation among either Māori or Pacific Islanders contribute to these higher rates (Bryant et al. 2009; Carapetis et al. 2000). Rather, the ethnic disparities can be linked to socio-economic disadvantage, including overcrowding, increased exposure to GAS bacteria, and decreased healthcare access (Jaine et al. 2011; Milne et al. 2012b; Wilson 2010).

In 2011, the New Zealand government initiated the Rheumatic Fever Prevention Programme (RFPP) 
with the aim of cutting rheumatic fever admissions by two thirds. The major emphasis of this programme is not on primordial prevention, but on treating strep throat infections with antibiotics. Atrisk children who experience a sore throat are offered free swabbing through primary care clinics and some schools to test for the streptococcus A bacteria that signals a strep throat infection. ${ }^{1}$

At Tūrama School, the primary school where I conducted a year of fieldwork, one of these sore throat clinics operated out of a disused classroom. ${ }^{2}$ The school is located in South Auckland, has approximately 400 pupils, roughly $70 \%$ Māori and 25\% Pasifika, and is ranked by the Ministry of Education as a decile one school, which means that it serves some of the most socio-economically disadvantaged children in the country. Following ethics approval, I positioned myself as an ethnographer and 'classroom helper' enquiring about children's health experiences. I gained child assent and parent consent to conduct participant observation alongside 82 children from the six senior classes (aged 8 to 12), and interviewed 38 children, seven school staff and six caregivers. Following Mayall (2000) and Christensen (2004), I adopted the role of 'different kind of adult' to negotiate the stark lines of authority drawn between children and adult staff in an institutional setting: while I did not attempt to deny my adult status and privileges, I visibly and transparently followed different social rules from other adults. I sat on the floor with the children rather than on a chair with the teachers, turned a blind eye to misbehaviour, and, when children came to 'tell' on a classmate, suggested that they go tell a teacher instead. Children quickly became accustomed to these rules and would inform other children and adults, saying 'she likes to sit on the floor' and 'she's not a teacher'. This position, while not unproblematic (for instance, when I received disclosures of harm that the children indicated would not have been volunteered to a 'real' adult), did allow me to have better access to children's worlds and the various ways in which they resisted, negotiated and appropriated adult structures - including the way they experienced and used the Türama School sore throat clinic.

As part of the morning routine, every day teachers asked their class: 'Who has a sore throat?' Those who put their hands up were sent to the clinic to be swabbed, while Allison, the clinic community health worker, also visually checked all children's throats twice a term to catch those who had not selfidentified. While observing this process, I became intrigued with a dilemma that Allison and the clinic nurse Deb were facing. A large number of children self-identified as having a sore throat on almost a weekly basis, but rarely tested positive for strep. The main issue was the expense; each swab cost about $\mathrm{NZ} \$ 15$, and the clinic staff felt an obligation to manage government resources responsibly. On the other hand, they did not want to dissuade children from coming forward if they genuinely had a sore throat. Yet their suspicion was that many of these children were just here to 'muck around' and get out of class.

Children's use of the Tūrama School clinic was consistent with district-wide evidence that showed that while swabbing numbers had increased since the programme commenced, the proportion of swabs returning a positive result had decreased (Anderson et al. 2016). Over the first seven months of my fieldwork, around $9 \%$ of 1,434 swabs for self-identifying children (range: $2 \%-20 \%$ ) came back positive for streptococcus $\mathrm{A}^{3}$ The number of swabs taken over the course of my fieldwork averaged seven swabs a year for each child, although this figure underestimates the number of children presenting with sore throat, as Allison would not swab children who were waiting for swab results or already taking antibiotics. The nurses' dilemma therefore reflects a broad pattern of children's participation in their healthcare at Türama School, one where children were not passively receiving care according to adult expectations, but actively engaging in unexpected ways with the care provided to them.

Anthropological work has demonstrated how illness events, including clinical encounters, are embedded within complex sets of social relations, cultural ideas and power dynamics which shape how care is given and received. While perspectives developed from medical anthropology such as cultural competency are increasingly recognised in health policy, there persists a tendency to overlook children also as social actors and producers of cultural ideas. In the case of rheumatic fever policy, the design, implementation and ongoing evaluations of the RFPP components have involved parents and caregiver perspectives, but those of children, the passive sufferers of disease and recipients of care, fade into the background of policy documents (Vermillion Peirce et al. 2015; Anderson et al. 2016; Ministry of Health 2013; Ministry of Health 2015). For example, evaluations recognise that parents do not typically think of children's sore throats as requiring a doctor visit, and that standard practice is for parents only to 'keep an eye on' their child (Ministry of Health 2013). A large component of the promotional campaign has therefore been to emphasise that sore throats can kill. 'It's 
not cool to take the risk', goes a poster headline. 'Get your child's sore throat checked every time'. The sadeyed child sitting in a hospital surgery room is meant to incite parents to take their child's sore throat seriously, but while it tested the campaign on its target audience of parents, the Health Promotion Agency did not consider how children would view these images. ${ }^{4}$ Other evaluations include the views of young people (adolescents) but not younger children, or only test children's health literacy via survey (i.e. whether they have heard of rheumatic fever) while soliciting the full experiences of adult family members in focus groups (Anderson et al. 2016; Ministry of Health 2015). Hence, while children are the target of these policies and programmes, their experiences and perspectives are largely invisible.

Here is where child-centred medical anthropology can shine a light on how child policy operates from the perspectives of children themselves. I build on the work of Christensen (1999) to analyse how the major interventions of the RFPP restructured the processes through which children constructed understandings of their bodies and illness, and how children created their own social practices around accessing the clinic. First, children produced varied understandings of 'sore throat' where their experience of the body met verification in the clinic. Second, children's etiological models of rheumatic fever progression and risk were derived from a media campaign and reinforced through peer cultures. Third, some children appropriated the Tūrama School clinic to play a role in their peer relations, though the script of 'getting out of class' may also have functioned to allow children to mask their vulnerability to peers and access care. These examples demonstrate how children's active engagement with their experience of policy can have unintended consequences.

\section{Reconciling the Body Incarnate and the Body Somatic}

In her work with Danish schoolchildren, Christensen (1999) provides an important theoretical explanation of the processes through which children come to recognise illness. She observed the tendency of children to both bring minor ailments - such as a brief sensation of nausea - to the attention of adults and accept or adapt on their own to more serious ailments - for example, by sitting closer to the television in response to short-sightedness. These observations are mirrored in the Tūrama School context, where some children presented themselves to teachers and the nurses with 'sore throat' on a weekly basis, while other children, identified through a class check to have throats so swollen that the nurses wondered how they could breathe or eat, were seemingly unaware of their condition.

While these two things may seem contradictory, Christensen argues that they demonstrate how these children's understanding of health and illness reflects a process of learning to translate the subjective experience of the 'incarnate' body into symptoms and sicknesses according to local cultural classifications and models of body parts and their functioning, the 'somatic' body. Christensen draws on the work of Ronald Frankenberg (1980) and Allan Young (1982), who recognise that biological or behavioural signs in the body are interpreted in culturally specific ways and come to be socially recognised as 'symptoms' of illness. Christensen (1999) adds to this that recognising unusual signs as illness is not a kind of intrinsic ability that people are born with, and that children must learn to identify and distinguish signs of illness from other kinds of uncomfortable or unpleasant experiences of the body. The body is normally very changeable, so actors are not necessarily able to recognise an 'out of the ordinary' bodily sensation. As children grow up, they come to learn and engage with a complex interpretive and classificatory process of understanding that some bodily sensations of discomfort or pain are accepted as 'normal' while others are not.

This learning process involves the conversion of bodily sensations into symptoms of illness through several social processes. When children bring feelings, injuries or bodily signs of illness to the attention of adults, the adult will determine whether the children are 'really sick', often using technical equipment such as thermometers. Once they have established that the children are sick, adults will administer treatment and separate the children from one another by bringing them to the sick room or by keeping them at home. Thus, children link their experience of the incarnate body to its cultural classification through the verification of illness by adult authority and by the symbolic experience of what happens next: staying home, being cared for, drinking or eating certain things, and ingesting medicine. Notably, for the child being ill means that 'I cannot do what I usually do' (Christensen 1999: 187), a state which could be experienced as annoying, but which also signifies their illness as an event of significance. Finally, Christensen (1999: 210) observes children engaging with peers in a 'collective bricolage of the body': they draw on their social experiences and knowledge of the body 
to link bodily experiences to the 'somatic' body. Thus, peer groups make significant contributions towards children's understandings of illness, both as sources of information about bodily experiences, and also as collaborators in the project of connecting those experiences to cultural models or classification systems.

\section{Creating Sore Sore Throat}

I am arguing here that the Türama School clinic restructures these processes of linking subjective experiences of discomfort to the diagnosis of illness, resulting in the production of new understandings of illness, and that it does so in such a way that children are more likely to present to the clinic to be swabbed. This occurs because the prevention programme is primarily based on a subjective symptom - sore throat - and because it relies on children to identify when they have a sore throat either by telling their teacher and presenting at the clinic or by telling a parent so that they may be taken to the doctor to be swabbed for strep throat. This process presupposes that children have acquired an adult conception of the link between the incarnate experience of a painful throat and the somatic understanding of some forms of this experience as a symptom labelled 'sore throat'.

This is an assumption that I initially made myself, and had some very confused moments in interviews before thinking to ask ten-year-old Anton, 'What is a sore throat?' 'Like the fever, you know? Coughs and that, sneezing and that, cold and that.'

After I started asking, I got all sorts of descriptions, some of which represented a traditional or clinical idea of sore throat, but many of which did not. Alzea (age 10) thought that the flu and sore throat were the same, associating both conditions with coughing, a headache and blocked or painful swallowing from coughing too much. For Trystan (age 11), a sore throat was 'when you're coughing and stuff. And your throat gets hot and that'. Navahn (age 11) saw it as an allergy where 'you can't eat' and 'there's lumps'. Meanwhile, children who have connected a painful throat to the label 'sore throat' often do not differentiate between sore throats with known causes, such as 'talking too much' or 'eating scratchy food' from sore throats that could represent a symptom of illness. Thus, children's somatic understanding of sore throat did not match the adult biomedical model.

Compounding the variable understandings of sore throat is a lack of clarity about the difference between sore throat - the symptom - and strep throat as one specific cause of sore throat. Media campaigns focus on sore throat, with little mention of strep throat, while nurses speak of children being 'positive', usually without specifying for what. For many children, then, sore throat and strep throat become conflated, and sore throat comes to be understood in somatic terms as its own condition, diagnosed by the clinic staff or the lab. As a result, ten-year-old Mila came to the clinic not because she felt a painful throat, but 'so the nurse can check if I have a sore throat'. Tenyear-old Ngawaina created her own terminology to differentiate between her experience of sore throat symptoms and the clinically diagnosed condition that requires treatment:

Ngawaina: I don't think my throat was... sore sore.

Julie: It wasn't sore sore.

Ngawaina: I don't think so.

Julie: What's the difference between sore sore and not sore sore?

Ngawaina: Sore sore is like... you really need medicine? And not really sore is when... you just need a good night (sic) rest?

In this context, children's 'illness' is also being verified by adults in a very explicit and formal way, an institutionalisation of the everyday social process where adults validate children's illness claims and help them to link the body incarnate to the somatic body. Like what Christensen observed in her study of Danish adults and children, the Tūrama School sore throat checks involved adult devices that demonstrated adult competencies and signified illness. Allison would take the children's temperatures, weigh them, look in their mouths with a torch, feel their neck glands and swab their throats. The children payed close attention to the results of these assessments, and in particular the sheet of paper where they were recorded. 'And every time I come here, she puts me down as a redness and swollen', Amberlee (age 10) told me. 'Because I watch her, and when she does that it actually kind of freaks me out'. Importantly, Allison circled 'sore throat' on the form to record children's self-reported symptoms, but for children watching this confirmed that their 'sore throat' was real. Children therefore do not need the lab results; the assessment, swabbing and recording process is in itself the verification which confirms children's bodily sensations - whatever they may be - as sore throat. Hence, 'sore throat' becomes not only a subjective experience, but also a condition which is externally diagnosed. 
To further complicate things, sometimes children do not experience a painful throat, but are identified in a class check and swabbed. In such instances, sore throat becomes something that you might not know you have. This experience was very powerful for Mila, who had been 'given the medicine' (diagnosed with strep throat) multiple times, but who had never experienced a sore throat. 'But sometimes I do have sore throats but I don't actually feel it?' she told me. 'So, I'll just think that I've got nothing to worry about?' Because Mila is unable to link her diagnoses with any perceptible symptoms, she presents at the clinic regularly - 'twelve times this year', she estimated in November - so that Allison could check whether or not she had a sore throat.

Thus, the connections children make between subjective sensations of the body incarnate and the illnesses of the somatic body are reconfigured by the school clinic; any symptoms, even an absence of symptoms, can be verified by medical authorities as sore throat. The incarnate experience of sore throat becomes anything ranging from sneezes to absence of feeling, while the somatic category of sore throat shifts from a symptom to a diagnosis. Unlike the interactions that Christensen (1999) observed, children are not simply learning to classify their bodily experiences according to adult concepts of illness, but are also creating their own concepts and classifications - sore throat the symptom, and sore sore throat the illness - to explain the inconsistencies between their experience and their diagnosis. This creative production of illness concepts continues in the construction of rheumatic fever.

\section{Children's Knowledge of Rheumatic Fever}

Two shirtless, solemn boys gaze out from a large poster behind Allison's desk. With a long scar down one of the boys' chests clearly visible, they oversee the children getting their throats swabbed with the message: 'My brother almost died... it all started with a sore throat' and the slogan I had come to hear so often: 'Sore throat leads to rheumatic fever, leads to heart damage'. Inside or outside of the clinic, I heard children repeat the messages from the poster and from the related television campaigns. Elevenyear-olds Navahn and Trystan, who I interviewed in their classroom, told me that they knew about how rheumatic fever goes into the heart because they saw the poster in the clinic:
Navahn: It says my brother had-

Trystan: -rheumatic fever

Navahn: -ah rheumatic- oh, and it says it all started from a sore throat.

'Yeah that ad', said ten-year-old Te Kapua in another interview, reciting the message, 'My brother almost died. It started with a sore throat'.

This media campaign (Figure 1) was designed by New Zealand's Health Promotion Agency and includes posters which appear across bus shelters and buildings in targeted areas and a television campaign which first aired in 2014. The campaign was intended to target parents (particularly Māori and Pasifika parents), but has become a primary source of children's rheumatic fever knowledge. From what I could tell, little additional information was formally provided to the children in Türama School, although Allison would answer children's questions. When the clinic first opened, shortly before I began fieldwork, the clinic staff gave a talk in assembly, but this was not repeated in the time that I was there, and few children ever mentioned anything other than the media campaign as a source of their knowledge. An information pack went home to parents with consent forms, but this was not written with children's reading levels in mind. The nurse, Deb, gave me a long list of points that she covered with parents when advising of a positive diagnosis and delivering medicine, including storage, adherence, dosage, side effects, reactions and information for the doctor. When I asked what information Deb provided to the children, the things she listed were reminders - to remind mum and dad to give them the medicine, and to bring back their sticker chart - and discussions of their treatment experiences (but no factual information).

As a result, children's detailed and developed conceptualisation of rheumatic fever was constructed using the media campaign as scaffolding. Across the main elements - the sequence of three conditions, the link to death, the primacy of sore throat - children have spun their webs of meaning (Corsaro 1992), using their own experience and what they observed of those around them and filling in the gaps that adults left blank with knowledges of their own production. Thus, children's conception of rheumatic fever was consistently unified around a model of its aetiology, which is the most salient aspect. This model was expressed in three stages (or four, the fourth stage being death), and some children explicitly referred to numbered stages. 


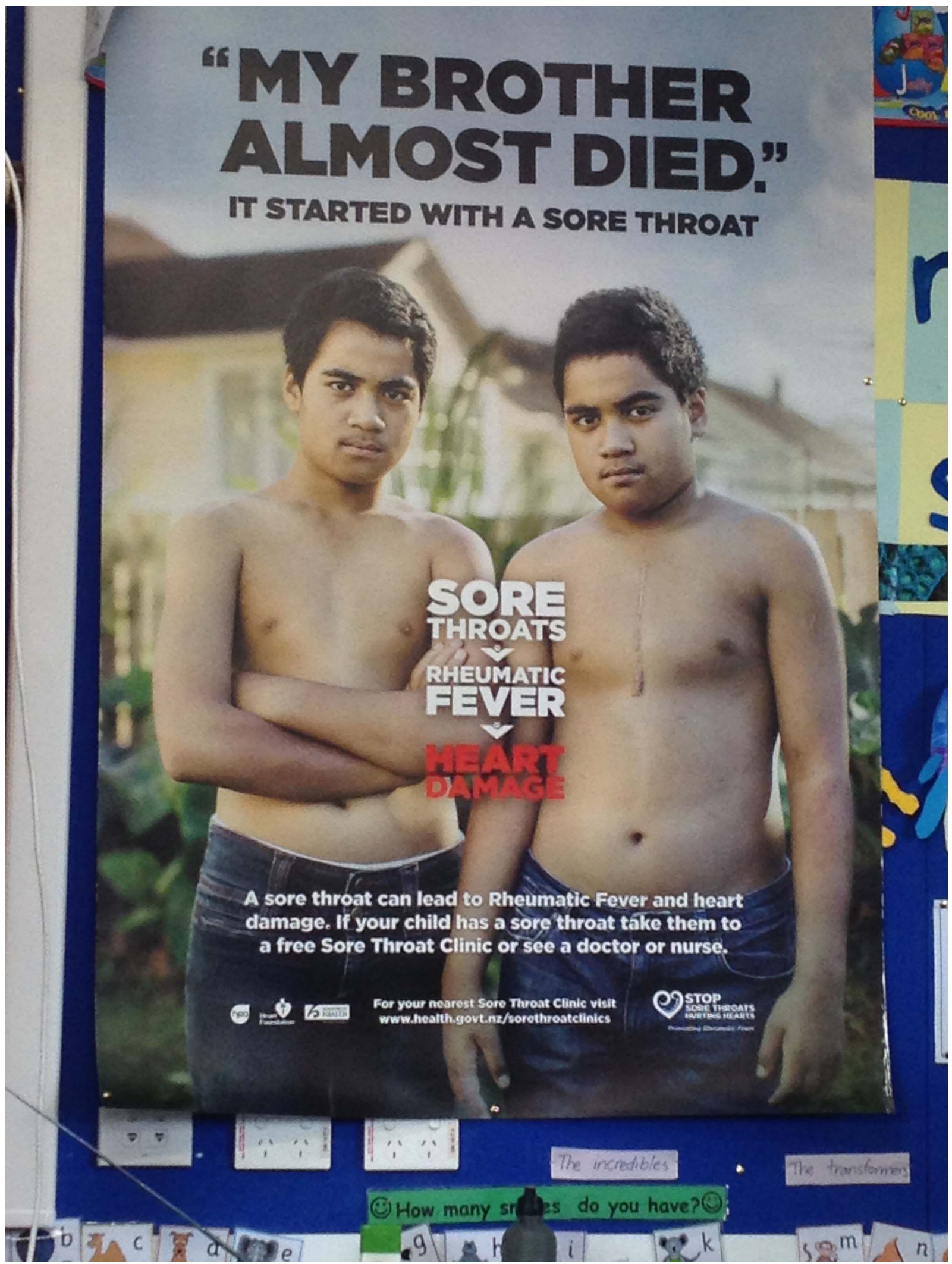

Figure 1. Campaign Poster for Rheumatic Fever in the Classroom Clinic. Poster produced by the Health Promotion Agency of New Zealand (photo by the author). 
In an interview in the clinic classroom after school, three ten- and eleven-year-old girls told me what they knew about rheumatic fever. In a collective bricolage reminiscent of Christensen's (1999) descriptions of Danish children, they linked their experiences and observations of 'what happens' and 'what you do' to the model of illness that was presented on the poster. Ruby responded first: 'Rheumatic fever, 'cause my cousin had it, and he only made it to the second one, and he almost made it to the heart thing, but they...'. She mumbled, perhaps unclear about what 'they' did to prevent heart damage.

'What do you mean, he only made it to the second one?' I asked. Ruby explained: "Cause like there's three aye, and you start from sore throat, then you get rheumatic fever, but he never got the things down there'. She pointed to the poster behind her. 'Oh, he never got the heart disease', I said, reading the poster. As Ngapaea and Alexandra, who had been distracted, tuned back into the conversation, I asked again: 'What do you know about rheumatic fever?' Ruby began: 'It starts from a sore throat...'. She was interrupted by Ngapaea: 'Oh it starts from a sore throat, then it goes to heart damage...'. Ruby then interrupted: 'No, it goes to rheumatic fever'. At this point, Alexandra jumped in: 'It starts with sore throat then rheumatic fever...' 'And then heart damage', all three girls chimed. 'And then dead', Alexandra finished.

This way of describing rheumatic fever was ubiquitous among these children. Stage one was the sore throat, which, as described above, was represented by a plurality of meanings. Children had a clear idea that if their sore throat was not checked it could get worse and progress to stage two, rheumatic fever. For most children, stage three, heart damage, was linked to death. As the girls explained:

Ngapaea: And the reason we have to have sore throat lady here is have to give 'em medicine to make- you might have heart damage. We get heart damage we're gonna have to end up in hospital and we have to-

Ruby: -No, 'cause we can- if- if we too late we can pass away-

Alexandra: -And if we get heart damage, we'll die.

Rheumatic fever was therefore conceptualised primarily in terms of its relationship to sore throat and heart damage and in terms of its perceived proximity to death, a linear series that would inevitably progress through the stages if no intervention was to occur. As noted earlier, few children included strep throat in their model, reflecting the absence of strep throat in the media campaigns. Consequently, it seems that many children, after receiving antibiotics, may have inferred that they were now at 'stage two' of this model and believed that they had rheumatic fever. Several children told me about their past history of rheumatic fever, but described the experience of having their throat swabbed by Allison or a doctor, and taking antibiotics for ten days. 'Heart damage, I just had that before. For just like two weeks', Anton told me. Some of these children told me that the doctor had told their mother that they had rheumatic fever, so it is unclear whether the communication issue was between doctor and parent, or whether the children reinterpreted the information from their parent and attributed their understanding to medical authority.

Yet because children would share their 'diagnosis' with their peers, the effect of this was to increase perceptions of the risk of sore throat progressing to rheumatic fever. 'Jackson's got rheumatic fever!' an eleven-year-old girl hissed across the classroom when Jackson was called to the clinic to receive his antibiotics. Children would also commonly attribute the illness or deaths of family members to rheumatic fever. Contrary to how rheumatic fever is represented in the media campaign, child death from acute rheumatic fever is extremely rare, though it is possible that some adult deaths may have represented early mortality from the effects of chronic rheumatic heart disease. However, for others it later transpired that the cause of death had been another illness such as pneumonia. Though actual incidences of rheumatic fever remain relatively rare, and though most children are likely not even susceptible to it, as a collective these rheumatic fever narratives created a sense of the disease as much more commonplace, inevitable and deadly than the epidemiological data would suggest.

By contrast, the one child I knew of in the senior school who actually did have heart valve damage from a prior bout of rheumatic fever hid his condition from his peers. Nine-year-old Victor would tell his class he was in trouble with the principal when he was called to the office to meet the district health nurse who visited Türama School to administer his monthly prophylactic penicillin injections. Had he chosen to make his experiences more visible, it is possible that his peers may have used this information to distinguish rheumatic fever prevention from its treatment.

While the children matched their experiences and those of their peers to the model presented in the campaign, the process of connecting the incarnate and somatic bodies was also restructured by the spatial 
marking of illness. Similar to the children of Christensen's (1999) study, the Tūrama School children (and likely their parents also) associated being sick with staying home and taking medicine. Though the nurse told me that she would try to explain to the parents that their children only needed to stay home from school if they felt too unwell to go, several children told me that they stayed at home for the entire ten-day duration of the antibiotics course, despite a lack of symptoms. Ten-year-old Cassidee told me that when the 'doctors' told her mum that she had rheumatic fever they said 'that I had to stay home for like, two weeks. That was boring'. Staying at home had the effect of symbolically marking their experience as illness, and children who stayed at home, like Cassidee, were also more likely to be those who interpreted their illness as 'rheumatic fever'.

In contrast to sore throat, the children's models placed less emphasis on symptoms, exactly what rheumatic fever is or how it might be experienced. That the most salient incarnate experience of 'rheumatic fever' for Cassidee was boredom makes sense, given that any strep throat symptoms likely subsided within a day or two of receiving antibiotics. However, for nine-year-old Marielle, who had given me detailed descriptions of the rheumatic fever campaign, it appeared that the fear of her diagnosis may have formed her incarnate experience of what she understood to be 'rheumatic fever'. Even in my interview with her, she gasped between words, unconsciously re-enacting the embodied memory of the illness that she associated with breathlessness. 'I thought I was gonna die because it was my first time', she told me. 'Rheumatic fever is how... um, you can't breathe properly? Well you can't, well you can breathe but you can't breathe properly, and um, you get heart damage sometimes, if you're, if you got that very, if you got rheumatic fever too long? And it can be caused by um, sore throats'.

Marielle described the breathlessness as having started after she had gone to the doctor:

Like after. And then I was like, thinking... what just happened? .... Then I was thinking, like I was gonna be that boy? [in the campaign] Like you know, huh, I was like... ahhhh, I've gotta take my pills!

The nurse later confirmed to me that strep throat was not associated with breathing difficulties, and Marielle's breathlessness was most likely anxious hyperventilation, which was perhaps triggered by the thought that she too would be like the boy on the poster who almost died. Thus, while the children constructed a somatic understanding of rheumatic fever around a model of its aetiology, linking campaign information to their social observations and experiences, they also produced a 'rheumatic fever' incarnate, which was primarily experienced as emotions such as boredom and anxiety, and which was symbolically marked by staying home and taking medicine.

\section{Getting Out of Class}

The high number of children who attended the Türama School clinic can therefore be partially attributed to the restructuring of children's knowledge production, through which children collectively generate new understandings of illness and the body to guide their practices. However, Christensen (1999) also describes how moments of illness forefront the very social notions of privacy, intimacy, weakness and vulnerability associated with feeling unwell. Consequently, illness events accentuate children's social relations - status, hierarchies, relationships enacted, for example, in who children notify of an illness event (siblings) and who stays by the sick child while they receive help (close friends). Illness and healthcare are therefore closely intertwined with children's peer cultures not only through the production of knowledge, but also in the production of relationships.

The situating of the clinic within the school further amplifies the social nature of healthcare in this context, and this may also help to explain children's use of the clinic. When I asked about children's reasons for visiting the clinic, most children said that they went only to get their throats checked. Several children also complained that teachers sometimes did not believe that their sore throat was real and prevented them from visiting the clinic. However, as the nurses suspected, some children did suggest that they, or other children, went to the clinic to get out of class. This seemed to be connected to Allison's practice of bringing children to the clinic as a class group, rather than individually, which transformed clinic visits into a social event. Amara, a shy nine-year-old who floated at the edge of peer groups, giggled with me that she 'sometimes' wanted to get out of class; for her, following the more socially successful children to the clinic may have meant an opportunity to strengthen her relationships. Sometimes, 'my friends say put your hand up so you can come too', Cassidee told me, but on days when she was the only girl who put up her hand, she would visit the clinic by herself at lunchtime for a swab, rather than go with the boys. 
Clinic visits could also offer a moment of respite from the stresses of the classroom environment, and large groups of children attended the clinic particularly from two classes where the teachers yelled constantly throughout the day. Amberlee, on the other hand, complained that the clinic staff 'always come at the wrong time' - that is, when she was doing something enjoyable and did not want to leave the classroom.

The clinic, therefore, could be appropriated by children into the construction of their social relations. However, as well as offering peace and social time, talk of getting out of class could perhaps sometimes function as a discourse for children, particularly those with 'tough' reputations, to justify going to the clinic to peers. Eleven-year-old Trystan, the tallest and oldest boy in his class, first suggested that he used the clinic to get out of class, while his friend and co-interviewee Navahn, drawing gang imagery with the art materials I had supplied, also added that too much running around caused them to cough. However, later in the interview Trystan talked about the recent death of his aunt, who he said was like a mother to him, and his own experience at the hospital the previous year, which he said was due to rheumatic fever. Navahn commented that his uncle had died from rheumatic fever, or maybe it was pneumonia, or maybe heart damage; he was not sure which one it had been. 'Has that scared you a bit?' I asked them nonchalantly. 'Yeah', they replied. 'I might get it again', said Trystan. 'Yeah, I'm scared of getting rheumatic fever', added Navahn. 'Are you really?' I ask, a little surprised at their serious tone. 'Yeah. I don't want to go to the hospital. I don't want to die', said Nahvan. Then he continued: 'I'd rather kill myself. Nah jokes, jokes!' He laughs, grabs my recorder and apologises loudly to the speaker, melodrama and mockery steering him away from the edge of vulnerability that he has just found himself too far out on.

It is possible that Trystan and Navahn feigned a fear of death to cover a well-honed practice of escaping the classroom. But for these boys who live in a world of gangsters and toughness, skipping class may also represent a public excuse to mask a vulnerability which does not fit their staunch social personas. Their processes in this interview, one moment reflecting on fear of an illness that seems to saturate their world, the next calling each other a stink arse, suggest in themselves an ambivalence about why they are doing what they are doing. If death is an underlying fear turned into a joke, then creating a cultural routine of skipping class also entrenches a socially - and emotionally - acceptable pathway to seeking care.

\section{Conclusion}

This ethnographic approach to children's health experience reveals a multi-dimensional set of social processes underlying their use of the clinic as part of their practices of care. This contrasts with a health policy that does not acknowledge children's agency in their healthcare and assumes an understanding of how the programme will work in practice based on adult biomedical models of health and the body, and disembedded from the social context of the school.

Yet children's encounters with healthcare interventions represent critical spaces for their active engagement in processes of knowledge production and the negotiation of their social position, both of which, at a school-based clinic, occur in the midst of their peer cultures. Thus, school clinics help to mediate children's collective project of calibrating bodily experiences with the somatic, culturally classified understanding of the body. With its intensive focus on the subjective experience of sore throat, the Tūrama School clinic and associated media campaigns profoundly restructured this process, resulting in children's production of novel understandings of sore throat and rheumatic fever. Further, the unusual clinical procedure of examining children in groups turned healthcare into a social event, whether children appropriated the clinic as a relationshipbuilding opportunity, or established social routines to make accessing care more comfortable or socially acceptable. These processes shaped children's patterns of accessing healthcare in ways that were not predicted by a health policy which did not consider them as significant social actors.

This article points to the value of child-centred anthropology for promoting the visibility of children in public policy. Drawing from a long history of advocacy for marginalised groups, anthropology is wellplaced to challenge ethnocentric assumptions about childhood. Ethnographic methodologies, anthropology's bread and butter, are also particularly useful for understanding the perspectives of children who may be less practised at verbal articulation but who can nonetheless express their experiences through multiple other, embodied or relational modes. The challenge, perhaps, is to bring insights out of anthropology and across to other disciplines, practitioners and policy-makers. 
Julie Spray is a doctoral candidate in anthropology at the University of Auckland specialising in childhood and medical anthropology. Her doctoral thesis explores children's experiences of health and illness in South Auckland.

E-mail: j.spray@auckland.ac.nz

\section{Notes}

1. Risk factors in this context include having a personal, family or household history of rheumatic fever, Māori or Pacific ancestry, being aged 3 to 35 years old and living in crowded circumstances or a low socio-economic area (Lennon et al. 2014).

2. Name of school and participants are all pseudonyms.

3. The data sets were provided to me in a personal communication by Mana Kidz (https://www.healthpoint .co.nz/public/community/mana-kidz/im:430534/).

4. Personal communication.

\section{References}

Alderson, P. (1993), Children's Consent to Surgery (Buckingham, England: Open University Press). Anderson, Philippa, Julian King, Michelle Moss, Phil Light, Tracy McKee, Elizabeth Farrell, Joanna Stewart and Diana Lennon (2016), 'Nurse-Led SchoolBased Clinics for Rheumatic Fever Prevention and Skin Infection Management: Evaluation of Mana Kidz Programme in Counties Manukau', New Zealand Medical Journal 129, no. 1428: 36-45.

Bluebond-Langner, M. (1978), The Private Worlds of Dying Children (Princeton: Princeton University Press).

Bryant, Penelope A., Roy Robins-Browne, Jonathan R. Carapetis and Nigel Curtis (2009), 'Some of the People, Some of the Time Susceptibility to Acute Rheumatic Fever', Circulation 119, no. 5: 742-753.

Carapetis, Jonathan R., B. J. Currie and J. D. Mathews (2000), 'Cumulative Incidence of Rheumatic Fever in an Endemic Region: A Guide to the Susceptibility of the Population?' Epidemiology and Infection 124, no. 2: 239-244.

Christensen, Pia Haudrup (1999), 'Towards an Anthropology of Childhood Sickness: An Ethnographic Study of Danish Schoolchildren' (PhD Diss., University of Hull, England).

Christensen, Pia Haudrup (2004), 'Children's Participation in Ethnographic Research: Issues of Power and Representation', Children \& Society 18, no. 2: 165-176.
Corsaro, W. A. (1992), 'Interpretive Reproduction in Children's Peer Cultures', Social Psychology Quarterly 55, no. 2: 160-177.

D'Souza, A., L. Signal and R. Edwards (2017), 'Patchy Advances in Child Health Hide a Systematic Failure to Prioritise Children in Public Policy', New Zealand Medical Journal 130, no. 1450: 12-15.

Elizabeth, V. and W. Larner (2009), 'Racializing the "Social Development" State: Investing in Children in Aotearoa/New Zealand', Social Politics 16, no. 1: 132-158.

Frankenberg, R. (1980), 'Medical Anthropology and Development: A Theoretical Perspective', Social Science \& Medicine 14, no. 4: 197-207.

Hunleth, J. (2017), Children as Caregivers: The Global Fight against Tuberculosis and HIV in Zambia (New Brunswick, NJ: Rutgers University Press).

Jaine, R., M. G. Baker and K. Venugopal (2008), 'Epidemiology of Acute Rheumatic Fever in New Zealand 1996-2005', Journal of Paediatrics and Child Health 44, no. 10: 564-571.

Jaine, R., M. G. Baker and K. Venugopal (2011), 'Acute Rheumatic Fever Associated with Household Crowding in a Developed Country', The Pediatric Infectious Disease Journal 30, no. 4: 315-319.

James, A. and A. Prout (1990), Constructing and Reconstructing Childhood: Contemporary Issues in the Sociological Study of Childhood (London: Falmer Press).

Keddell, E. (2018). 'The Vulnerable Child in Neoliberal Contexts: The Construction of Children in the Aotearoa New Zealand Child Protection Reforms', Childhood 25, no. 1: 93-108.

Lennon D., B. Peat, M. Kerdemelidis, N. Sharpe and R. Liddle (2014), New Zealand Guidelines for Rheumatic Fever Group A Streptococcal Sore Throat Management Guideline: 2014 Update (Auckland: Heart Foundation New Zealand).

Mayall, B. (1996), Children, Health and the Social Order (Buckingham, England: Open University Press).

Mayall, B. (1998), 'Towards a Sociology of Child Health', Sociology of Health \& Illness 20, no. 3: 269-288.

Mayall, B. (2000), 'Conversations with Children: Working with Generational Issues', in P. Haudrup Christensen and A. Prout (eds.), Research with Children: Perspectives and Practices (London: Falmer Press), 120-135.

Milne, R. J., D. R. Lennon, J. M. Stewart, S. Vander Hoorn and P. A. Scuffham (2012a), 'Mortality and Hospitalisation Costs of Rheumatic Fever and Rheumatic Heart Disease in New Zealand', Journal of Paediatrics and Child Health 48, no. 8: 692-697.

Milne, R. J., D. R. Lennon, J. M. Stewart, S. Vander Hoorn and P. A. Scuffham (2012b), 'Incidence of 
Acute Rheumatic Fever in New Zealand Children and Youth', Journal of Paediatrics and Child Health 48, no. 8: 685-691.

Ministry of Health (2013), 'Implementation and Formative Evaluation of the Rheumatic Fever Prevention Programme: Final Report', Wellington: Ministry of Health. http://www.health.govt.nz/ our-work/diseases-and-conditions/rheumatic-fever/ rheumatic-fever-publications.

(2015), 'Formative Evaluation of Sore Throat Clinics', Wellington: Ministry of Health. http://www .health.govt.nz/our-work/diseases-and-conditions/ rheumatic-fever/rheumatic-fever-publications.

Montgomery, H. (2001), Modern Babylon? Prostituting Children in Thailand (New York: Berghahn Books).

O'Brien, M. (2016), 'The Triplets: Investment in Outcomes for the Vulnerable - Reshaping Social Ser- vices for (Some) New Zealand Children', Aotearoa New Zealand Social Work Review 28, no. 2: 9-21.

Tap, R. (2007), ‘High-Wire Dancers: Middle-Class Pakeha and Dutch Childhoods in New Zealand', Doctoral Thesis, University of Auckland.

Vermillion Peirce, P, S Akroyd, and P Tafuna. (2015), 'Evaluation of the 2015 Rheumatic Fever Awareness Campaign', Wellington, N.Z.: Ministry of Health. http://www.health.govt.nz/publication/evaluation2015-rheumatic-fever-awareness-campaign.

Wilson, N. J. (2010), 'Rheumatic Heart Disease in Indigenous Populations-New Zealand Experience', Heart, Lung and Circulation 19, no. 5: 282-288.

Young, A. (1982), 'The Anthropologies of Illness and Sickness', Annual Review of Anthropology 11: 257-285. 